\title{
"I Just Want Them to See Me As...Me": Identity, Community, and Disclosure Practices Among College Students on the Autism Spectrum
}

\author{
Kyle M. Frost, MA, ${ }^{1}$ Kathryn M. Bailey, BS, ${ }^{2}$ and Brooke R. Ingersoll, PhD, BCBA-D ${ }^{1}$
}

\begin{abstract}
Background: The purpose of this project was to understand how college students on the autism spectrum integrate their diagnosis into their identity, whether they connect with a broader "autism community," and when and why they disclose their diagnosis to other people.

Methods: Twenty participants completed semistructured interviews by phone, text message, or email. An inductive approach was used to generate codes, and results were synthesized via thematic analysis, theme counts, comparing and contrasting cases, and examining outliers.

Results: Across participants and interview topics, the students in our study expressed a desire to be understood and known genuinely by other people. Interviews revealed that autistic identity is complex and variable across individuals. Most of the students in our study did not feel part of a broader autism community, although several reported that some of their close friends were on the spectrum as well. Our participants rarely disclosed their autism to other people, and this decision was often informed by whether the disclosure would support or inhibit understanding.

Conclusions: Results suggest there is a need for neurotypical people to be more accepting, affirming, and empathetic in their interactions with neurodivergent people. In addition, our results suggest that autistic college students may not participate in services that explicitly connect groups of students on the spectrum or require disclosure of their diagnosis. College students with autism should be involved in the development of college supports and services that are consistent with their values and disclosure practices.
\end{abstract}

Keywords: autism identity, disclosure, autism community

\section{Lay Summary}

What was the purpose of this study?

The purpose of this study was to understand how autistic college students integrate autism into their identity, whether they feel a part of a larger "autism community" and when and why they tell other people that they have autism.

\section{What did the researchers do?}

The researchers in this study interviewed 20 autistic college students. Interviews included several topics: (1) how autism fits into students' sense of identity, (2) whether they feel connected to an autism community, and (3) whether, when, and why the students tell others they are on the autism spectrum. Researchers read the interview transcripts and identified common themes based on what students said.

What were the results of the study?

Overall, the college students in this study wanted to be genuinely understood by others. Some students identified strongly as autistic, whereas others felt it was not part of who they are. Most students in this study did not feel a part of a larger autism

\footnotetext{
${ }^{1}$ Department of Psychology, Michigan State University, East Lansing, Michigan.

${ }^{2}$ Department of Special Education, Vanderbilt University, Nashville, Tennessee.
} 
community, but several reported having friends on the spectrum. Most participants did not tell others about their autism diagnosis; however, they felt comfortable sharing this information with close friends, romantic partners, and school personnel. In general, decisions about disclosing (or not disclosing) were related to being understood by other people.

\section{What do these findings add to what was already known?}

This study focused on the experience of autistic college students from their own perspective and discussed relationships between disclosure practices, autistic identity, and connection to autism communities in a way other studies had not done before. This study's findings suggest a need for neurotypical people to be more accepting, affirming, and empathetic toward people with autism. In addition, because college students on the autism spectrum may not use services that require disclosure of their diagnosis, colleges should allow autistic students to be involved in the development of services that meet this population's unique needs.

\section{What are potential weaknesses in the study?}

This study only recruited participants from disability resource centers of colleges in the midwestern United States, so results may not apply to other people. Students who had not registered with disability services could not be contacted for participation in this study. Furthermore, most participants in this study were white men from families with a high level of education, so we have a limited ability to understand how being autistic might intersect with other facets of identity for members of other marginalized groups.

\section{How will these findings help autistic adults?}

These findings help the autism community by informing the neurotypical population about the need to be more accepting of the unique perspectives of people on the autism spectrum. Although autism awareness in the United States has increased, our results suggest that awareness alone is not enough. Instead, our goal should be to promote acceptance, inclusion, and empowerment of autistic people.

\section{Introduction}

$\mathbf{O}$ WING TO A VARIETY OF FACTORS, more autistic students are enrolling in colleges and universities than ever before. ${ }^{1-3}$ However, there is limited understanding of how autism fits into the identity of college students on the spectrum, whether students affiliate with an autism community, and factors that influence why and to whom they disclose their diagnosis.

There are a variety of perspectives on autism as a social identity. Many individuals on the autism spectrum have challenged the traditional medical conceptualization of autism, and instead conceptualize autism as a difference rather than a disability. ${ }^{4,5}$ This view promotes a collective identity, and sees autism as central to one's individual identity. ${ }^{6}$ However, autism does not always play a role in people's identities. ${ }^{7}$ For example, one study found that some college students with autism prefer to distance themselves from the diagnosis. ${ }^{8}$ Likewise, many individuals with disabilities (more broadly) do not see themselves as disabled, and may not describe disability as central to their identity. ${ }^{9}$

Autism is an "invisible" disability, thus, the challenges and needs experienced by autistic individuals may not be apparent to others. Therefore, autistic people can often choose whether and when to tell people they are on the autism spectrum. Disclosing an autism diagnosis is a complex social decision, and requires people to identify safe targets for disclosure. ${ }^{10}$ Autistic adults are often careful about disclosing their diagnosis, and may behave in specific ways to conceal their autism in some situations. ${ }^{11}$ This is referred to as "camouflaging," which comprises both masking certain behaviors and compensating with others to manage people's perceptions of certain stigmatized behaviors. ${ }^{12,13}$ Recent research suggests that although certain behaviors associated with autism remain stigmatized, being labeled as autistic might improve first impressions by neurotypical college students. ${ }^{14}$
Decisions about whether, when, and to whom college students with autism disclose their diagnosis are not well documented in research. Extant research suggests that autistic students resist disclosing their diagnosis, but do so when they have a specific support need, can no longer cope with stress, or when they feel safe. ${ }^{15}$ Disclosure in academic settings may occur to obtain academic accommodations, and also has specific legal protections. Thus, it is not surprising that autistic college students more often self-identify to college disability centers and professors than to peers. ${ }^{16}$ Students cite past negative reactions and fear of stigma, prejudice, or rejection as reasons for not disclosing to peers. ${ }^{15}$ However, students do sometimes disclose to peers for practical reasons. ${ }^{17}$ These findings suggest that many college students with autism are selective in their decisions to disclose their diagnosis. However, the extent to which an autistic identity plays a role in their decisions to disclose is unclear.

\section{Purpose}

The purpose of this project was to understand, from their perspective, (1) how college students on the autism spectrum integrate autism into their identity, (2) whether they feel connected to a broader "autism community," and (3) when and why they disclose their diagnosis. This study adds to the current body of literature by focusing on the experience of autistic college students, and investigating the relationship among disclosure practices, autism identity, and connection with a broader autism community for this population.

\section{Methods}

\section{Participants and recruitment}

Participants in this study were current college students formally diagnosed with autism spectrum disorder (ASD), 
who were recruited through disability resource centers at 4year public colleges and universities in the midwestern United States. Disability resource center staff distributed flyers to protect individuals' confidentiality. To be eligible for this study, individuals had to (1) have an ASD diagnosis, (2) be enrolled in a degree-seeking college program that was not solely online, (3) provide informed consent, and (4) opt in to the interview portion of this study. This project was approved by the institutional review board at Michigan State University.

On average, our participants were 23 years old (standard deviation $=6.7$ ). They came from seven different public universities; $47 \%$ had attended another university or community college before their current institution. Participant pseudonyms and demographic information are provided in Table 1

\section{Procedure}

The semistructured interview data for this study were collected as part of a broader mixed methods study regarding the experiences of college students with autism (Bailey, Frost, Casagrande and Ingersoll, under review). Participants were given the option to complete the interview by phone, text message, or email to increase accessibility and acceptability of the research. ${ }^{18}$

The portion of the interview discussed here included questions on three topics: autism as a social identity, affiliation with an autism community, and practices around disclosing the autism diagnosis. The interview guide is included in the Appendix. Twenty participants completed the interview (10 phone, 4 text message, 5 email, and 1 email and phone; Table 1). Phone interviews were recorded and transcribed verbatim. The first and second authors removed speech dysfluencies from participant quotations as needed to improve clarity (e.g., removal of "um" and repetitions of words or parts of words), with care taken not to change the meaning of the responses we received.

\section{Data analyses}

First, we sought to identify themes as they naturally emerged in the interviews; therefore, an inductive thematic analysis was used. During a first pass through the transcripts, the first and second authors developed preliminary descriptive codes consistent with the process of "open coding." 19 Codes were subsequently refined and organized into higher level and lower level codes within four broad themes. Interviews were coded a second time by both the first and second authors together after all codes were finalized. Next, we began the process of interpreting our findings and drawing together meaningful conclusions. ${ }^{20} \mathrm{We}$ independently reviewed the coded excerpts and created separate organizations and explanations of the data. We also examined code frequencies and patterns of co-occurrence among our themes. The final phase of analysis involved testing and verifying our findings. To accomplish this, we examined outliers in our data, as well as compared and contrasted extreme cases. ${ }^{20}$ Together, these methods helped us to build a better explanation of our data, and to better understand the interaction between sense of community, disclosure, and social identity.

\section{Author positionality}

The article authors include a postbaccalaureate researcher, graduate student researcher, and a faculty researcher in a department of clinical psychology. All authors have a research focus on autism, and a commitment to supporting autistic individuals and their families. All have direct experience working with individuals with autism, and one has an immediate family member who is autistic.

Table 1. Participant Pseudonyms, Interview Format, and Demographic Information

\begin{tabular}{|c|c|c|c|c|c|}
\hline Pseudonym & $\begin{array}{l}\text { Interview } \\
\text { format }\end{array}$ & Race, ethnicity & Gender & $\begin{array}{c}\text { Age } \\
\text { (years) }\end{array}$ & $\begin{array}{l}\text { Highest parent } \\
\text { education level }\end{array}$ \\
\hline Adam & Text & White, Hispanic/Latino & Male & 20 & Graduate degree \\
\hline Amy & Email & White & Female & 22 & HS diploma/GED \\
\hline Benjamin & Text & White & Male & 24 & Some college \\
\hline Brittany & Phone & White & Female & 29 & Graduate degree \\
\hline Cameron & Phone & White & Male & 20 & Bachelor's degree \\
\hline Carter & Phone & White & Male & 19 & Graduate degree \\
\hline Dante & Phone & Black & Male & 20 & Bachelor's degree \\
\hline Ethan & Phone & White & Male & 19 & HS diploma/GED \\
\hline Greg & Phone & White & Male & 18 & Graduate degree \\
\hline James & Phone & White & Male & 21 & Bachelor's degree \\
\hline Jamie & Email/phone ${ }^{a}$ & White & Nonbinary & 22 & Some college \\
\hline Justin & Text & White & Male & 20 & Bachelor's degree \\
\hline $\mathrm{Kim}$ & Email & White & Female & 31 & Associate's degree \\
\hline Mark & Phone & White & Male & 22 & HS diploma/GED \\
\hline Michael & Phone & White & Male & 48 & Bachelor's degree \\
\hline Rob & Email & White & Male & 21 & Graduate degree \\
\hline Ryan & Text & White & Male & 19 & Graduate degree \\
\hline Samantha & Email & White & Female & 22 & Graduate degree \\
\hline Steven & Email & White & Male & 21 & Associate's degree \\
\hline Zara & Phone & Black & Female & 20 & Graduate degree \\
\hline
\end{tabular}

${ }^{a}$ Participant began the interview over email, and finished it over the phone. GED, General Equivalency Diploma; HS, high school. 


\section{Member check}

Participants were given the opportunity to read this article, make comments, and suggest edits. One person returned feedback. This participant said that the article was well written, and two brief comments were accounted for in a subsequent revision.

\section{Note on language}

To best represent the voices of our participants, we asked whether they preferred identity-first language (i.e., "autistic people") or person-first language (i.e., "people with autism") for the purposes of this article in a brief follow-up survey. Four of the eight respondents preferred person-first language, and one preferred identity-first language. Two respondents reported no preference, and one suggested alternating. Therefore, we chose to intermix person-first and identity-first language, to represent the variability in our participants' responses.

\section{Results}

Participants in our study spoke about how autism fits into their identity, whether they feel connected to a broader community of autistic people, and the extent to which they disclose to others. Across topics and interviews, participants' responses pointed to a desire to be genuinely understood and seen as individuals by the people around them. In the following sections, we show how this broad theme was present across individuals, despite differences in individual identity, connection with the autism community, and decisions about disclosure.

\section{Identity variability}

Interviews with our participants revealed that, for college students on the autism spectrum, autism identity is complex and highly individualized. An equal number of participants said that autism is a substantial part of their identity $(n=6)$ and that autism is not a part of their identity $(n=6)$, with others falling somewhere in between $(n=3)$. Some participants named positive outcomes of being on the autism spectrum, mentioning either a sense of pride for being autistic or otherwise naming the strengths that come with having autism. For example, Carter described the aspects of autism that are beneficial to him, "Like we're hyper-analytical, on a whole we're very good with making connections, like... putting two and two together, and trying to figure things out.",

Other participants reported negative feelings about their autism. Some of these participants reported that they do not like having autism, whereas some noted that they struggle with conditions that often co-occur with autism. Brittany said:

[...] when I am sort of in the grips of my comorbid disorders that come with it, like anxiety, depression, OCD, I dislike it more. [...] But, like, I try not to personally identify with it because during my low periods of time, it makes me feel like I'm broken in a way.

Ambivalence was also common, with several participants describing mixed feelings about how autism fits in to their identity. For example, Justin, who felt that autism was a large part of his identity, said, "I see it as a double-edged sword. It comes with challenges but also with gifts that make me who I am."
In addition, the complexity of intersecting identities was mentioned by Zara, who is a Black woman. For her, both Blackness and being autistic are barriers to being understood:

I don't want to be stereotyped [...]. I'm Black too, so people have certain types of stereotypes and certain types of ideals associated with that, so, all of a sudden when you also say that you're autistic, it's like that's another building block for them."

It appears that, for college students with autism, the integration of autism and personal identity is variable and highly individualized. For autistic college students, sense of identity is influenced by both the strengths and challenges of having autism, in addition to the comorbid conditions and intersecting identities that may affect an individual's experience.

\section{Distance from community, but closeness to individuals with autism}

Few participants reported feeling part of a broader autism community $(n=2)$, whereas the majority did not $(n=13)$. Many participants said that the reason they do not belong to a community is because they do not feel that they relate to others with autism. For these students, having an autism diagnosis in common with someone does not immediately form a sense of belonging or community. For example, Ethan said:

Um, I wouldn't say I really belong in a community of sorts. Like okay so for years back when I was younger, my dad tried to force me into like these social groups who involved other people on the autism spectrum. And, and I think the problem was that, that he was trying to force something that needed to come naturally.

However, despite not explicitly feeling connected to an autism community, some participants reported a sense of connection with others who are on the spectrum $(n=3)$, or noted that many of their friends happen to be autistic as well $(n=3)$. This included the student mentioned, Ethan, who also said, "I happened to by chance have ended up in a group where all of us are on the autism spectrum. That doesn't define us. That's, that's just sort of a side bag."

Participants stated that they did not want to belong to an autism community for a variety of reasons. Some described these communities as being stigmatizing, whereas others did not feel as though they fit in within an autism community. Brittany said, "I mean, I know other people around me who do have the dis - who are on the spectrum, but in general, I'm more in a group of neurotypicals than with other people on the spectrum." Participants also gave other reasons for not belonging to an autism community, including that communities may emphasize stereotypes about autism, and that being diagnosed later in life made it hard to find autism communities.

Only two participants felt that they belonged to an autism community. Justin, who was the only participant who often disclosed his diagnosis to others, shared:

Yeah, I tend to communicate well with others on the spectrum even though all Aspies are different. At least with the verbal Aspies it seems like we all speak a similar dialect of social cues that differ from those of people not on the spectrum. 
Across interviews, our participants wished to be genuinely understood by others. This desire led most of our participants to distance themselves from any broader autism community, even when they had many close friends on the autism spectrum. In many cases, this represented an attempt to avoid judgment and stigmatization. Participants who felt a part of an autism community seemed to value their increased understanding of others with autism, and embraced these communities because they felt understood by other autistic individuals as well.

\section{Limited disclosure}

The vast majority of our participants rarely disclosed their autism diagnosis to other people $(n=15)$. Only one individual often shared this information with others, and three did so sometimes. Many participants, including those who rarely disclosed to others, said they shared this information with close friends and long-term romantic partners. In addition, many people mentioned disclosure to professors or other school personnel for the purpose of obtaining accommodations. Interestingly, both decisions to disclose and to refrain from disclosing the diagnosis were often couched in the desire to avoid judgment and misunderstanding from others. Some students felt that disclosing was a hindrance to being understood, whereas others felt that this information could facilitate understanding. Jamie, who rarely disclosed their diagnosis to others, expressed:

\begin{abstract}
It's not easy for me to be open about, $[\ldots]$ because people don't know what to do with the information. They have preconceived notions, it might cause things like being singled out or being perceived as, this preconceived notion of what a person is like instead of what I am as an individual. [...] so the people I've told tend to be only other people who are openly autistic or are people who are openly disabled in other ways. $[\ldots]$ because of, like I said, the fear of stigmatization.
\end{abstract}

In other words, for this participant, disclosing to other people who are autistic or otherwise disabled allowed them to be known by those individuals, without fear of judgment. Otherwise, sharing this information was perceived as detrimental to being understood.

Other participants disclosed their diagnosis in an effort to avoid negative judgment, or to facilitate understanding. For example, Dante said he disclosed his diagnosis when asked directly. He said, "Um, just giving them a good explanation on my verbal communication and everything. I just want them to know so that way they don't talk about me, like 'Oh man. Why is he so weird?',' Similarly, Brittany, who disclosed to others somewhat more frequently, used disclosure to help people understand her:

For example, if I'm in a new place of employment, and I meet a manager for the first time- $[. .$.$] I tell them that I am on$ the spectrum so that way, I can explain how I best process information and why I might view things differently than your typical person.

Justin was the only individual who reported frequent disclosure. He stated that being an "Aspie" or having Asperger syndrome was a large part of his identity. When asked about disclosure, he said, "I pretty much tell everyone I interact with for any moderate amount of time that I am on the
Table 2. Disclosure Characteristics Data Table

\begin{tabular}{|c|c|}
\hline $\begin{array}{l}\text { Individuals to whom } \\
\text { participants disclosed }\end{array}$ & $\begin{array}{l}\text { Close friends (8) } \\
\text { School personnel (7) } \\
\text { Romantic partners (4) }\end{array}$ \\
\hline Reactions to disclosure & $\begin{array}{l}\text { No change }(15) \\
\text { Supportive/understanding (9) } \\
\text { Surprise }(5) \\
\text { Treated worse }(5)\end{array}$ \\
\hline Reasons for disclosing & $\begin{array}{l}\text { During relevant situations }(5) \\
\text { To explain unusual or awkward } \\
\text { behavior ( } 2 \text { ) } \\
\text { To facilitate understanding (2) }\end{array}$ \\
\hline $\begin{array}{l}\text { Reasons against } \\
\text { disclosing }\end{array}$ & $\begin{array}{l}\text { Fear of judgment or } \\
\text { misunderstanding ( } 7) \\
\text { Viewed by others as an excuse or } \\
\text { attention seeking ( } 3) \\
\text { Not wanting to be treated } \\
\text { differently (2) }\end{array}$ \\
\hline
\end{tabular}

spectrum [...] I just don't really care about hiding it.' He shared that his autism diagnosis is an important part of his identity; thus, disclosure was important to helping others understand him. This participant's experience is an outlier among the participants in this study; however, much like our other participants, his decision regarding disclosure was related to being understood by others.

Although disclosure was rare, our participants reported various nuances in terms of who they told, why, and how people reacted (Table 2). When disclosure occurred, it was most often with close friends, school personnel, and long-term romantic partners. Likely because of the caution with which people disclosed their diagnosis, our participants generally had positive experiences. Most participants reported no change in how they were treated by people after disclosing, and many participants said that the people they told were supportive and understanding in response. For example, Rob said: "When I was in distress about something that seemed simple, I told the people around me, and they were accepting of it." However, some people did report having negative experiences with disclosure, which affected their propensity to disclose in the future. Kim said: "The times I've tried only made everything worse." Although concealing one's identity may have its own repercussions, our participants were largely successful in determining when and to whom they could safely disclose their diagnosis.

\section{Discussion}

One of the aims of this study was to understand, from their perspectives, how college students on the autism spectrum integrate autism as part of their identity. Across interviews, it became clear that autistic identity is complex and highly individualized. Even among students who reported autism as central to their self-identity, strong identification with the broader autism community was rare. This suggests, at least for these students, the development of an autism self-identity may proceed independently from development of an autism collective identity. Other possibilities are that these students have not yet attempted to access a broader autism community (but may in the future), or have found past attempts off-putting or unaccommodating. Longitudinal research is needed to understand how affiliation with an autism community may develop and change over time. 
One relevant feature of this sample is that all our participants were college students, and nearly all were in the developmental stage of "emerging adulthood," which is characterized by, among other things, identity exploration, instability in education, vocation, and relationships, and a focus on the self. ${ }^{21,22}$ Even outside of this developmental period, identities vary across time; Identity Management Theory posits that cultural identities are negotiated and renegotiated within relational contexts, and that the scope, intensity, and salience of identities vary dynamically across situations and relationships. ${ }^{23,24}$ Given that identities are relational in nature, ${ }^{23}$ it follows that a change of setting in combination with the development of new relationships and interests might lead to an increased intensity and salience of some facets of identity over others. This is supported by previous research in a college student population, which also found varying levels of engagement and identification with autism as a social identity. ${ }^{8}$ Additional research is necessary to understand how this facet of identity development changes over time, and whether it relates to other outcomes.

Despite the varying extents to which our participants identified with autism as a social identity, a desire to be known authentically, treated equally, and understood by others emerged as a common theme. In many cases, this informed disclosure practices. Some students felt they could be better understood if people knew they were autistic; however, many feared being judged or stereotyped, and delayed disclosure until after developing close relationships. However, our participants often felt safe disclosing to school personnel to obtain support.

Importantly, even students who identified strongly as autistic chose not to share this information with most people. Consistent with previous research, some of our participants shared stories about negative experiences with disclosure, and many deliberately refrained from sharing this information with most people for fear of judgment or misunderstanding. ${ }^{11,15}$ This self-protective decision may also have negative repercussions. Research suggests that concealing a largely invisible stigma, such as mental illness, chronic health conditions, disability, or sexual orientation, has psychological costs in terms of mental health, cognition, affect, behavior, friendship goals, and interpersonal interactions. ${ }^{25-27}$ For individuals on the autism spectrum, concealing autism often involves "camouflaging" social difficulties. ${ }^{12} \mathrm{Ca}-$ mouflaging has been associated with an increased likelihood of depression, as well as exhaustion, anxiety, and stress in adults with autism. ${ }^{12,28}$ This speaks of a need for neurotypical people to be more accepting of the perspectives and behavior of neurodivergent people, and to learn how to interact with people in a way that is empathetic and affirming. Although autism awareness in the general population of the United States has been increasing, the experiences of our participants suggest that awareness is not sufficient. ${ }^{29}$ Instead, a more worthy goal would be acceptance, inclusion, and empowerment of neurodivergent and disabled people.

The findings of this study also have implications for service access. Most of our participants did not identify as part of a broader autism community and many were hesitant to disclose their autism diagnosis to others. This suggests that college students may not opt into groups or services targeting autism explicitly, because they do not identify as such or share that information freely. In addition, social groups that are centered on the idea of autism as a shared identity may not be attractive to students who are not drawn to an autism community. Rather, it may be more useful for disability services offices to help students locate and join clubs, sports, or other student organizations that align with their interests and promote social connection in a natural and authentic way. Autistic college students should be engaged by colleges and universities in the development and implementation of services and supports that align with their values and needs.

\section{Limitations}

For practical purposes, our study sample was recruited from disability resource centers of higher education institutions in the midwestern United States. This limits the generalizability of this research study in a few ways. First, students must have had some encounter with the disability resource centers before recruitment, requiring a certain level of disclosure and identification as a person with a disability. Research suggests that $\sim 30 \%$ of young adults with autism do not consider themselves to have a "disability or special need," 30 and these results likely do not capture the views of people who chose not to register with the disabilities office. Second, this study focuses on college students. This is a subset of autistic individuals who communicate verbally, are privileged in their ability to attend college, and who are in a formative stage of developing many facets of identity. Therefore, the perspectives discussed here may not apply to older adults, teens, people who do not attend college, and those who do not communicate verbally. In addition, most of our participants were white men from families with a high level of education, which limited our ability to understand how being autistic might intersect with other facets of social identity for members of multiple marginalized groups. Last, this study recruited a small sample of participants; therefore, results may not be generalizable to the population of autistic college students more broadly.

\section{Future directions}

Although the idea of "camouflaging" was not discussed explicitly by our participants, the infrequency with which the college students in our study shared their diagnosis with others suggests that this is a relevant area for future research. This topic has gained limited attention in the research literature; however, autistic individuals report experiencing exhaustion, stress, and anxiety as a result of camouflaging. ${ }^{12}$ In the long term, this can lead to what autistic people describe as "autistic burnout.",31,32 Future research should attempt to understand the relationship between disclosure practices, camouflaging, and poor mental health outcomes.

Other research studies have recruited from active participants in a broader autism community, and from individuals for whom autism is a central feature of their identities. However, the results from this study suggest that many autistic college students may distance themselves from broader autism communities. Places such as online forums and in-person support groups are useful for finding individuals who disclose their diagnosis more freely and actively seek connection with other people on the spectrum; however, these may not be optimal for recruiting those individuals who do not share this information with others. Future research including adults with autism should involve sampling from places other than active autism 
communities to include the perspectives of those who avoid groups centered around autism.

\section{Acknowledgments}

First and foremost, we thank all of the individuals who took the time to participate in our interviews. This research would not have been possible without their willingness to discuss these topics candidly. We also thank the members of the MSU Autism Lab for transcribing interviews, providing advice on data analysis, and reviewing drafts of this article.

\section{Authors' Contributions}

K.M.F. contributed to the study design, data analysis, and writing of this article. K.M.B. contributed to the study design and data analysis, conducted participant interviews, and assisted with article preparation. B.R.I. contributed to the research question and study design, and assisted with article preparation and revision. This article has been submitted solely to this journal and is not published, in press, or submitted elsewhere.

\section{Author Disclosure Statement}

All authors report that no competing financial interests exist.

\section{Funding Information}

There are no funding sources to report.

\section{References}

1. VanBergeijk E, Klin A, Volkmar F. Supporting more able students on the autism spectrum: College and beyond. $J$ Autism Dev Disord. 2008;38(7):1359.

2. White SW, Elias R, Capriola-Hall NN, et al. Development of a college transition and support program for students with autism spectrum disorder. J Autism Dev Disord. 2017; 47(10):3072-3078.

3. Adreon D, Durocher JS. Evaluating the college transition needs of individuals with high-functioning autism spectrum disorders. Int School Clin. 2007;42(5):271-279.

4. Robertson SM. Neurodiversity, quality of life, and autistic adults: Shifting research and professional focuses onto reallife challenges. Disabil Stud Quart. 2010;30(1). http://dsqsds.org/article/view/1069/1234 (accessed September 17, 2019).

5. Nicolaidis C. What can physicians learn from the neurodiversity movement? Virtual Mentor. 2012;14(6):503-510.

6. Bagatell N. From cure to community: Transforming notions of autism. Ethos. 2010;38(1):33-55.

7. Huws JC, Jones RS. Diagnosis, disclosure, and having autism: An interpretative phenomenological analysis of the perceptions of young people with autism. J Intellect Dev Disabil. 2008;33(2):99-107.

8. MacLeod A, Lewis A, Robertson C. "Why should I be like bloody Rain M an?!' Navigating the autistic identity. $\mathrm{Br} J$ Spec Educ. 2013;40(1):41-49.

9. Watson N. Well, I know this is going to sound very strange to you, but I don't see myself as a disabled person: Identity and disability. Disabil Soc. 2002;17(5):509-527.

10. Johnson TD, Joshi A. Disclosure on the spectrum: Understanding disclosure among employees on the autism spectrum. Ind Organ Psychol. 2014;7(2):278-281.
11. Davidson J, Henderson VL. "Coming out" on the spectrum: Autism, identity and disclosure. Soc Cult Geogr. 2010;11(2):155-170.

12. Hull L, Petrides K, Allison C, et al. "Putting on my best normal": Social camouflaging in adults with autism spectrum conditions. J Autism Dev Disord. 2017;47(8): 2519-2534.

13. Butler RC, Gillis JM. The impact of labels and behaviors on the stigmatization of adults with Asperger's disorder. $J$ Autism Dev Disord. 2011;41(6):741-749.

14. Sasson NJ, Morrison KE. First impressions of adults with autism improve with diagnostic disclosure and increased autism knowledge of peers. Autism. 2019;23(1): 50-59.

15. Van Hees V, Moyson T, Roeyers H. Higher education experiences of students with autism spectrum disorder: Challenges, benefits and support needs. J Autism Dev Disord. 2015;45(6): 1673-1688.

16. Gelbar NW, Shefcyk A, Reichow B. A comprehensive survey of current and former college students with autism spectrum disorders. Yale J Biol Med. 2015;88(1):45.

17. Cox BE, Thompson K, Anderson A, et al. College experiences for students with autism spectrum disorder: Personal identity, public disclosure, and institutional support. $J$ Coll Stud Dev. 2017;58(1):71-87.

18. Haas K, Costley D, Falkmer M, Richdale A, Sofronoff K, Falkmer T. Factors influencing the research participation of adults with autism spectrum disorders. J Autism Dev Disord. 2016;46(5):1793-1805.

19. Strauss A, Corbin J. Basics of Qualitative Research. Thousand Oaks, California: Sage Publications; 1990.

20. Miles MB, Huberman AM, Huberman MA, Huberman M. Qualitative Data Analysis: An Expanded Sourcebook. Thousand Oaks, California: Sage; 1994.

21. Arnett JJ. Emerging adulthood: A theory of development from the late teens through the twenties. Am Psychol. 2000; 55(5):469.

22. Murray JL, Arnett JJ. Emerging Adulthood and Higher Education: A New Student Development Paradigm. New York, New York: Routledge; 2018.

23. Cupach WR, Imahori TT. Identity management theory: Communication competence in intercultural episodes and relationships. In: Wiseman RL, Koester J, eds. Intercultural Communication Competence. Newbury Park, CA: Sage; 1993;112-131.

24. Merrigan G. Negotiating personal identities among people with and without identified disabilities: The role of identity management. In: Braithwaite DO, Thompson TL, eds. Handbook of Communication and People with Disabilities. Mahwah, NJ: Lawrence Erlbaum; 2000;223238.

25. Pachankis JE. The psychological implications of concealing a stigma: A cognitive-affective-behavioral model. Psychol Bull. 2007;133(2):328.

26. Newheiser A-K, Barreto M. Hidden costs of hiding stigma: Ironic interpersonal consequences of concealing a stigmatized identity in social interactions. J Exp Soc Psychol. 2014;52:58-70.

27. Lattanner MR, Richman LS. Effect of stigma and concealment on avoidant-oriented friendship goals. J Soc Issues. 2017;73(2):379-396.

28. Lai M-C, Lombardo MV, Ruigrok AN, et al. Quantifying and exploring camouflaging in men and women with autism. Autism. 2017;21(6):690-702. 
29. DeVilbiss EA, Lee BK. Brief report: Trends in US National autism awareness from 2004 to 2014: The impact of national autism awareness month. J Autism Dev Disord. 2014; 44(12):3271-3273.

30. Shattuck PT, Steinberg J, Yu J, et al. Disability identification and self-efficacy among college students on the autism spectrum. Autism Res Treat. 2014;2014:1-7.

31. Boren R. Autistic Burnout: The Cost of Coping and Passing. In: Ryan Boren: \#ActuallyAutistic Parent and Retired Tech Worker. 2018. https://boren.blog/2017/01/26/autisticburnout-the-cost-of-coping-and-passing/2017 (accessed September 5, 2018).
32. YouTube. Ask an Autistic \#3-What is Autistic Burnout? 2014. https://www.youtube.com/watch?v=DZwfujkNBGk\& feature=youtu.be (accessed September 5, 2018).

Address correspondence to: Brooke R. Ingersoll, PhD, BCBA-D Department of Psychology Michigan State University 316 Physics Road, Room 105B East Lansing, MI 48824

E-mail: ingers19@msu.edu

\section{Appendix}

\section{Appendix: Interview Guide}

I want to ask you a few more questions about whether and when you tell people that you are on the autism spectrum, and whether having autism is an important part of your identity.

- Some people with autism spectrum disorder (ASD) feel that it is an important part of who they are, whereas others do not feel that way. Is having autism an important part of your identity?

Some people might tell their friends, acquaintances, roommates, or professors that they have ASD, whereas other people choose not to.
- Do you tell others about your diagnosis? Who have you told?

o Did anything in particular prompt you to tell them?

o How did people respond?

- Do you feel as though you were treated differently afterward? (positively or negatively?)

- Are there ever times where you specifically decide not to tell people you have ASD?

$\circ$ Can you talk about why that is?

Note: Additional general probes (e.g., "Can you tell me more about that?" or "What do you mean by __") were permitted throughout. 